\title{
Ciências da Natureza na Educação do Campo: em defesa de uma abordagem sócio-histórica
}

\author{
Edilson Fortuna de Moradillo ${ }^{1}$, Hélio da Silva Messeder Neto ${ }^{2}$, Elisa Prestes Massena ${ }^{3}$ \\ ${ }^{1}$ Universidade Federal da Bahia - UFBA. Instituto de Química. Rua Barão de Jeremoabo, 147, Campus \\ Universitário de Ondina. Salvador - BA. Brasil. edilson@ufba.br. ${ }^{2}$ Universidade Federal da Bahia - UFBA. \\ ${ }^{3}$ Universidade Estadual de Santa Cruz - UESC
}

RESUMO. Este artigo trata da defesa da abordagem sóciohistórica nos cursos de formação de professores para atuação na área das Ciências da Natureza da Licenciatura em Educação do Campo, por considerarmos que esta abordagem é a que mais avança na análise crítica da realidade social e da educação, tendo como objetivo maior a emancipação humana. Para isso, apresentamos os princípios e pressupostos filosóficos, educacionais e pedagógicos que devem nortear o projeto político-pedagógico do curso. Defendemos que os referenciais do materialismo histórico-dialético, do Sistema de Complexos de Pistrak, da Pedagogia Histórico-Crítica e da Psicologia Histórico-Cultural sejam os norteadores dessa abordagem, tendo a categoria trabalho como fundante do ser social, o eixo condutor. Ao propormos a abordagem sócio-histórica ao trabalharmos a perspectiva historicizadora de homem e da realidade social, acreditamos que estamos avançando no sentido da luta contra hegemônica na educação e na sociedade na busca da emancipação humana.

Palavras-chave: Educação do Campo, Ciências da Natureza, Projeto Político-Pedagógico, Abordagem Sócio-Histórica. 


\title{
Natural Sciences in Rural Education: In defense of a socio- historical approach
}

\begin{abstract}
This article discusses the defense of the sociohistorical approach in the training courses for teachers to work in the area of Natural Sciences of the Degree in Rural Education, considering that this approach is the one that advances the most in the critical analysis of social reality and education, aiming at human emancipation. In this sense, we present principles and philosophical, educational and pedagogical presuppositions that should guide the pedagogical political project of the course. We argue that the referents of historical-dialectical materialism, the Pistrak's Complexes System, Historical-Critical Pedagogy and Historical-Cultural Psychology are the guiding principles of this approach, and the category of work is the founder and guiding axis of the social being. In proposing the socio-historical approach as we work the historicizing perspective of man and of social reality, we believe that there is an advance towards the hegemonic struggle in education and society in the search for human emancipation.
\end{abstract}

Keywords: Rural Education, Natural Sciences, PoliticalPedagogical Project, Socio-Historical Approach. 


\section{Ciencias de la Naturaleza en la Educación del Campo: en defensa de un enfoque socio-histórico}

RESUMEN. Este artículo trata de la defensa del enfoque sociohistórico en los cursos de formación de profesores para actuar en el área de las Ciencias de la Naturaleza de la Licenciatura en Educación Rural, por considerar que este enfoque es el que más avanza en el análisis crítico de la realidad social y de la educación, Teniendo como objetivo mayor la emancipación humana. Para ello, presentamos los principios y presupuestos filosóficos, educativos y pedagógicos que deben orientar el proyecto político pedagógico del curso. Defendemos que los referenciales del materialismo histórico-dialéctico, del Sistema de Complejos de Pistrak, de la Pedagogía Histórico-Crítica y de la Psicología Histórico-Cultural sean los orientadores de este abordaje, teniendo la categoría trabajo como fundante y el eje conductor del ser social. Con la propuesta del enfoque sociohistórico al trabajar la perspectiva historicizadora de hombre y de la realidad social, creemos que estamos avanzando hacia la lucha contra hegemónica en la educación y en la sociedad, en la búsqueda de la emancipación humana

Palabras clave: Educación del Campo, Ciencias de la Naturaleza, Proyecto Político Pedagógico, Enfoque SocioHistórico. 


\section{Introdução}

Tratar da Educação do Campo i e especialmente da área das Ciências da Natureza dos cursos de Licenciatura em Educação do Campo no contexto atual, de crise estrutural do capital com seus relativismos epistemológico e cultural, tem sido um grande desafio para os que defendem uma educação universalizante, que vá além dos seus particularismos, a exemplo do campo. A melhor forma que temos encontrado para realizar tal intento é através de um projeto político-pedagógico na perspectiva sócio-histórica, referenciado no materialismo histórico-dialético e na concepção de educação e prática pedagógica críticas.

Partimos do princípio de que a educação é um direito de todos e dever do Estado e deve ser garantida aos que vivem no campo, e que esta educação tem suas particularidades, distinta em vários aspectos daquela praticada nas zonas urbanas. Entendemos que algumas necessidades sócio-educacionais são outras, devendo a escola ser estruturada de acordo com o modo de viver, se relacionar, pensar e produzir das pessoas do campo, isto é, respeitando os seus costumes, valores, ritmos e interfaces com a vida produtiva. Entretanto, a nossa concepção de educação escolar e dos seus objetivos nos leva a propor uma escola que vá além dessas necessidades, pois defendemos que todos os seres humanos, do campo ou da cidade, precisam ser inseridos, de forma intencional, naquilo que a humanidade produziu de mais relevante na atualidade no campo cultural; para isso, não podemos abrir mão dos conhecimentos clássicos, socialmente relevantes e referenciados que foram universalizados, a exemplo da filosofia, arte e ciência. Do ponto de vista epistemológico, ético e ideopolítico, precisamos ir além do imediato, do cotidiano, dos particularismos, precisamos superar o espontaneísmo na educação e na sociedade, tão presente na realidade alienada e alienante das relações capitalistas de produção e reprodução da nossa existência. É isso que denominamos Educação do Campo.

A desigualdade estrutural da sociedade atual, fruto da estrutura classista que está materializada na propriedade privada dos meios fundamentais de produção e subsistência da nossa existência, repercute tanto na cidade como no campo, de modo que no campo os indicadores socioeconômicos mostram uma assimetria ainda maior (Projeto Político-Pedagógico, 2008).

Não podemos perder de vista que o campo, no Brasil, historicamente, a partir da invasão europeia no final do século XV 
e início do século XVI, com predominância portuguesa, que exterminou os proprietários da terra - os índios - e concentrou-a na mão de poucos, tem como característica a grande propriedade da terra - o latifúndio (Stedile, 2011). Essa invasão contou com a colaboração das instituições religiosas daquela época que, a pretexto de evangelizar, submetiam os índios ao domínio do invasor. Hoje encontramos os sem-terra, quilombolas, extrativistas, atingidos por barragens, povos indígenas que sobreviveram, dentre outros, geralmente apartados da terra como meio de produção da vida e em permanente conflito com os que detêm grandes quantidades de terra enquanto mercadoria e produção de capital - os latifundiários -, que são representados hoje pelo agronegócio. Portanto, ao defendermos e reivindicarmos a institucionalização da Educação do Campo, o fazemos com base em um projeto histórico que supere o projeto histórico capitalista.

Defendemos que essa educação como prática social que ocorre em uma sociedade de classes, em seu momento predominantemente capitalista, com repercussões no campo, e que está permeada de intencionalidade, deve se pautar em uma formação integral que tem como objetivo maior a emancipação humana.
A formação integral é o ponto de partida de qualquer projeto político pedagógico que tem como objetivo a emancipação humana. Por isso, a educação deve propiciar ao educando a superação da sua cotidianidade, da vida imediata, tornando-o um ser genérico e universal através dos conhecimentos socialmente relevantes, clássicos e sistematizados produzidos historicamente pela humanidade, elevando também a sua consciência de classe e a necessidade da transformação social. Esse aspecto também configura a Educação do Campo. Nesse contexto, a escola tem um papel importante como espaço possível de apropriação dos conhecimentos filosóficos, estéticos, da cultura corporal, artísticos e técnicocientíficos produzidos ao longo do processo histórico do homem produzir-se homem. O homem não nasce homem, se faz homem (Saviani, 1995; Leontiev, 2004; Marx, 2006; Marx \& Engels; 2007).

A educação que objetiva a emancipação humana desempenha um papel importante no sentido de disponibilizar para a classe trabalhadora os conhecimentos socialmente relevantes, sem a qual a consciência de classe tende a se amesquinhar e se alienar.

É com base nesse objetivo maior para a Educação do Campo - da emancipação humana - que defendemos 
que a melhor forma de realizá-lo na área das Ciências da Natureza no curso de Licenciatura em Educação do Campo é por intermédio de um referencial teóricometodológico que radicalize a análise da realidade social através de uma abordagem sócio-histórica. Como mencionado anteriormente, esse referencial tem como base principal o materialismo históricodialético e no campo educacional e pedagógico as teorias críticas.

Assim, apresentaremos inicialmente um breve histórico do curso de Licenciatura em Educação do Campo da Universidade Federal da Bahia UFBA/Salvador-Bahia e da atual experiência de estudo na Universidade Estadual de Santa Cruz - UESC/IlhéusBahia com a formação de professores na perspectiva crítica, com o objetivo de demarcarmos as nossas experiências recentes com a formação de professores na perspectiva sócio-histórica; em seguida, elencaremos os princípios e pressupostos para um curso na área das Ciências da Natureza, trazendo os principais princípios e pressupostos filosóficos, educacionais e pedagógicos que temos defendido e trabalhado. Por fim, concluiremos defendendo a categoria trabalho como fundamental para compreender e explicar a sociedade e como princípio educativo, sendo, consequentemente, a base para uma concepção de formação de professores na perspectiva sócio-histórica.

Esse trabalho tem o objetivo maior de contribuir para o norte dos projetos político-pedagógicos da área das Ciências da Natureza nos cursos de Licenciatura em Educação do Campo nas instituições de ensino superior brasileiras, principalmente os das universidades públicas, pautados numa perspectiva de formação de professores histórica e radicalmente crítica.

\section{O projeto da Licenciatura em Educação do Campo da UFBA e a recente colaboração com a UESC}

A Universidade Federal da Bahia (UFBA) fez parte do projeto piloto do curso de Licenciatura em Educação do Campo, proposto pelo Ministério da Educação, que tinha como objetivo implantar e pesquisar a formação de professores do campo. Esse projeto foi fruto da luta dos movimentos sociais, de suas experiências educacionais, assim como de projetos desenvolvidos entre universidades e Movimentos Sociais do Campo (Projeto Político-Pedagógico, 2008). Junto com a UFBA, três outras universidades fizeram parte desse projeto piloto: Universidade de Brasília (UnB), Universidade Federal de Minas Gerais (UFMG) e Universidade Federal de Sergipe (UFS). 
A UFBA teve as ações da Licenciatura em Educação do Campo implementadas e coordenadas pela Faculdade de Educação - FACED/UFBA em 2008, com colaboração de outras faculdades e institutos da UFBA, principalmente os Institutos de Química e de Letras. O curso foi estruturado e organizado para formar professores para atuar na Educação do Campo, em especial do $6^{\circ}$ ao $9^{\circ}$ ano do ensino fundamental e no ensino médio, por áreas de conhecimento: Ciências da Natureza e Matemática, Ciências Agrárias, Ciências Humanas e Sociais, Linguagens e Códigos, Tecnologias da Informação e Comunicação e teve duração de nove semestres. Dessas áreas, duas foram escolhidas para aprofundar a formação a partir do quinto semestre, a área das Linguagens e Códigos e a área das Ciências da Natureza e Matemática. O currículo foi organizado em 9 semestres letivos e o trabalho pedagógico em cada semestre alternava-se em um Tempo Escola e um Tempo Comunidade. O curso iniciou-se no segundo semestre de 2008, com uma turma, a qual concluiu o curso em abril de 2013. Essa turma contou inicialmente com 51 estudantesprofessores da região do Recôncavo e Nordeste do estado da Bahia, dos quais 5 desistiram durante o primeiro semestre. A partir do quinto semestre, dos 46 que deram continuidade ao curso, 15 optaram pela área das Ciências da Natureza e Matemática $^{\mathrm{ii}}$ e 31 pela área das Linguagens e Códigos (Moradillo et al., 2011).

Em agosto de 2013 realizamos um seminário avaliativo do curso que contou com as universidades parceiras do projeto piloto, dos estudantes e professores do curso e convidados, com os movimentos sociais e comunidade interessada. $\mathrm{Na}$ ocasião, concluímos que o curso teve uma experiência exitosa e que deveria se tornar permanente na UFBA. As decisões tomadas nesse seminário foram encaminhadas para as instâncias superiores da UFBA, e por falta de estrutura física, financeira e de pessoal, até o momento o curso não foi implantado como permanente. No segundo semestre de 2016, apesar do cenário político e econômico do país ser desfavorável para a criação de novos cursos, retomamos e refizemos o Projeto Político-Pedagógico do Curso da Licenciatura em Educação do Campo, com o objetivo de efetivá-lo no biênio 2017/2018, após novos entendimentos com a reitoria da UFBA e um possível apoio do Ministério da Educação através do Programa de Apoio à Formação Superior de Licenciatura em Educação do Campo Procampo. Essa nova proposta, inicialmente, prioriza uma única área de conhecimento: Ciências da Natureza. 
Devido a nossa experiência no curso anterior, nesse novo projeto estamos centrando a formação da área nas disciplinas de Química, Física e Biologia (a Matemática tem toda uma complexidade que achamos difícil de contemplar em um curso de formação de professores por área no tempo proposto). A Matemática será trabalhada no curso como "instrumento" articulado às necessidades das disciplinas citadas.

Em paralelo a isso, de outubro de 2016 até o momento, temos participado de atividades acadêmicas na Universidade Estadual de Santa Cruz - UESC que tratam da formação de professores de ciências na perspectiva crítica, em grupo de pesquisa que tem propiciado aproximações com o referencial trabalhado, denominado Situação de Estudo - SE.

A Situação de Estudo é uma proposta de intervenção e organização curricular que teve início por volta do ano 2000, por meio de um grupo de professores do Grupo Interdisciplinar de Pesquisa sobre Educação em Ciências (Gipec) da Universidade Regional do Noroeste do Estado do Rio Grande do Sul (Unijuí). Tem como base o estudo coletivo (professores das disciplinas escolares, principalmente de ciências exatas e matemática, e estudantes da escola básica, podendo envolver também professores e estudantes da universidade) de um tema oriundo do contexto de vivência dos estudantes, para que eles possam expressar as suas opiniões/impressões e conhecimentos prévios e, a partir daí, após aprofundamento teórico-prático, poder emergir os conceitos científicos das diversas disciplinas envolvidas no estudo, produzindo novos saberes (Maldaner, 2007; Massena, 2015).

Frutos dessas experiências, passaremos a expor agora os princípios e pressupostos filosóficos, educacionais e pedagógicos gerais que, em nosso entendimento, devem nortear a área das Ciências da Natureza no curso de Licenciatura em Educação do Campo na perspectiva sócio-histórica.

\section{Pressupostos e princípios filosóficos, educacionais e pedagógicos gerais}

Este item será subdividido em 3 subitens: o primeiro tratará de nosso posicionamento com relação ao papel das universidades públicas brasileiras na formação de professores; em seguida, abordaremos os princípios e pressupostos filosóficos gerais e, por último, os princípios e pressupostos educacionais e pedagógicos gerais que devem estar presentes na formação de um professor da área das Ciências da Natureza que se proponha crítica. 
a) Formação de professores nas universidades públicas brasileiras: para além do mercado

Aqueles que tratam o trabalho como constitutivo do humano e como fundante das relações sociais, reconhecem a dificuldade, no plano prático-político, para transformar o atual estágio da história da humanidade, determinada pelas relações capitalistas de produção, em que a alienação tem sido potencializada e a barbárie/desumanização tem sido a tônica. Os velhos discursos travestidos de modernos têm predominado em todos os espaços sociais, inclusive na educação. Por meio da ideologia (neo)liberal, que tem o mercado, com sua mão invisível, como fundante das relações sociais, a posição conservadora tem predominado (Moradillo, 2010).

É preciso também reconhecer que, por outros caminhos e de uma forma mais complexa, as teses e posturas pósmodernas $^{\text {iii }}$ têm ampliado e alimentado o debate, não necessariamente chegando, de forma direta, às mesmas teses conservadoras do mercado, porém diluindo ou negando o papel transformador dos sujeitos sociais, ainda mais daqueles que são obrigados a vender sua força de trabalho para sobreviver, com sérias implicações para a desigualdade social e a luta de classes (Moradillo, 2010; Moradillo et al., 2011).

As posturas pós-modernas, de uma forma geral, negam o papel revolucionário do sujeito social, negam as classes sociais na acepção marxista, negam a razão iluminista e o historicismo, o conhecimento totalizante e universalizante, a noção de verdade, inclusive da ciência, assim como a concepção de igualdade social e de emancipação humana. Como consequência, diluem o sujeito social nas suas particularidades de gênero, etnia, orientação sexual, raça, assim como de religião e, até mesmo, "econômica", dentre outras; de maneira resumida: diluem os sujeitos sociais nas suas "diferenças", e, dessa forma, supervalorizam, hiperdimensionam e inflacionam os particularismos sociais, denominados de diversidade "cultural"iv - o "multicuturalismo" -, resultando no relativismo epistemológico e cultural (Lyotard, 1997; Silva, 1999; Hall, 2001). Supervalorizam o "eu", em detrimento do "nós", que no limite nos torna indivíduosindividuais e não indivíduos-sociais. Tornamo-nos literalmente átomos sociais, cada um com a sua "visão" de mundo. O social só comparece como meio da minha realização pessoal. Assim, elevam a fragmentação do real à máxima potência (Wood \& Foster, 1999; Malanchen, 2016). 
Podemos também inferir que esses relativismos tendem a esconder, por trás das diferenças, as desigualdades sociais (transformam a desigualdade social em diferença) e, consequentemente, nas diferenças vamos nos tornando indiferentes à realidade social com seus antagonismos sociais de classe, da divisão social do trabalho e da propriedade privada dos meios fundamentais de produção da nossa existência, com implicações também éticas.

Dessa forma, as posturas pósmodernas acabam também reforçando as relações mercantis com suas consequências estruturantes devido à acumulação do capital: assimetria social em função da acumulação/riqueza de poucos em detrimento da miséria de muitos e destruição da natureza.

Esses discursos geralmente aparecem na educação na defesa intransigente das "diferenças" e do "multiculturalismo" (Malanchen, 2016), com seus desdobramentos nos projetos políticopedagógicos, nos currículos e nas concepções de ensino e aprendizagem.

Então, é nesse cenário de relativismo epistemológico e cultural imerso na sua base de sustentação, as relações capitalistas de produção da nossa existência e no seu momento histórico de crise estrutural (Mészáros, 2006a), com a sua reestruturação produtiva e crise do emprego (Coggiola \& Katz, 1996), que temos constatado uma tendência mais acentuada para adaptar a educação e a universidade às necessidades do mercado (Moradillo, 2010). Seja do ponto de vista da produção de conhecimento - de conformá-lo às necessidades práticas/tecnológicas do mercado -, seja do ponto de vista de formar profissionais para o mercado, com suas demandas. É sintomático que as Pró-Reitorias de Pesquisa de várias universidades tenham mudado o seu nome para Pró-Reitoria de Pesquisa, Criação e Inovação. Que saibamos, toda pesquisa tem como base a criação e inovação, portanto, seria redundante essa mudança de nome se o que está implícito nessa nova denominação não tivesse o endereço certo: criação e inovação para o mercado ${ }^{\mathrm{v}}$.

É preciso mais uma vez afirmar que as necessidades do mercado, com relação à mão de obra e ao conhecimento, mudam com uma velocidade diferente do processo educativo e das necessidades da sociedade como um todo. Não cabe formar pessoas ao sabor do vento do mercado e o mais importante, as pessoas não são mercadorias (Moradillo, 2010; Moradillo et al., 2011).

Por isso, defendemos uma proposta de universidade que vá além das necessidades do mercado, inclusive com 
relação aos modismos pedagógicos, que geralmente respondem a essas necessidades. Temos que agir no sentido de resgatar aquilo que é de fundamental importância para as instituições universitárias e que vem a ser o seu objetivo maior: a produção de conhecimento crítico (ir à raiz das coisas) e socialmente relevante (para além do mercado). Com base nesse princípio, defendemos que a formação de professores nas universidades radicalize a análise da realidade social através de referenciais filosóficos, educacionais e pedagógicos críticos, numa perspectiva sócio-histórica, enfrentando assim o chamado "recuo da teoria", que tem caracterizado essa formação, empobrecendo-a, acomodando-a aos modismos pedagógicos do momento (Moraes, 2003; Duarte, 2016).

Isso posto, passaremos a tratar agora dos princípios e pressupostos filosóficos gerais.

b) Pressupostos e princípios filosóficos gerais: ontologia do ser social e economia política

Trabalho como categoria fundante do ser social

Do ponto de vista materialista, o ser social surge a partir da sua base material e orgânica - a vida. Esse é o seu pedestal. Nesse surgimento, em termos da evolução, rompe com as características anteriores da matéria inanimada (determinação físicoquímica) e viva (determinação biológica), se caracterizando agora pela produção permanente do novo para dar conta da sua existência (determinação cultural). Assim, podemos falar de um salto ontológico nessa evolução. Esse "novo" é o constante movimento de produzir outro que não está posto na natureza, e que é a síntese dele ser social - com a natureza, através do trabalho. Esse é o processo de objetivação, que articula previa ideação (sujeito) e causalidade (natureza), pondo em movimento a realidade social, criando o mundo da cultura.

Chamamos esse processo de práxis social. Pela práxis social o ser humano transforma a ele e a natureza permanentemente, criando o mundo objetivo. A práxis social é o ato humano que, em contato com a realidade, articula o agir e o pensar, sempre permeado de valores sociais, procurando dar conta da sua existência - garantindo a reprodução social. Ao fazer isso, objetivando a realidade social, criando objetos materiais, ideias e instituições, cria-se a cultura.

Para dar conta da sua existência, o animal age de forma programada pela sua genética, ele é biologicamente determinado, a sua adaptação ao meio é passiva, se repete praticamente da mesma forma de geração para geração. A 
sobrevivência da espécie está intimamente ligada ao meio e a repetição dos seus atos o instinto -, o animal é equipado corporalmente com determinadas características que lhe permitem ser um especialista em seu meio. Os animais literalmente se adaptam à natureza, e tendem a repetir por várias gerações 0 procedimento padrão que a espécie traz no seu código genético (Moradillo, 2010).

O ser social é frágil corporalmente se o compararmos com vários tipos de animais, ele não é especialista em seu meio. Contudo, com a mediação do trabalho, ele consegue essa plasticidade que o caracteriza, e consegue se impor e ocupar quase todos os nichos existentes na superfície da Terra, podendo viver em ambientes extremos, a exemplo do deserto e das regiões geladas. Agindo sobre a natureza e transformando-a, o ser social segue para além da sua determinação biológica. Produzindo cultura dentro de relações sociais, onde a natureza é o princípio e o limite posto, supera por incorporação o biológico e passa a ser determinado por esse novo padrão socioambiental: a cultura. É a isto que estamos chamando de adaptação ativa: a determinação social e não biológica do ser humano (Moradillo, 2010). O homem não nasce homem, se faz homem (Saviani, 1995; Leontiev, 2004; Marx, 2006; Marx e
Engels; 2007). Para Marx (2006), a essência humana tem que ser buscada na prática, nas relações sociais, na materialidade terrestre e não no céu. As relações sociais passam a ser o fundamento da formação da espécie, tornando-nos seres genéricos, universais. Assim, a cada momento do desenvolvimento social, o homem - o ser social -, para dar conta da sua existência, transforma a si e ao entorno.

O ser social tem como marco fundante o trabalho, que é a ação deliberada - consciente - do homem na natureza para atingir determinados fins. Isto significa entender o homem como um ser que projeta, planeja e constrói o futuro e que, ao proceder assim, produz universalmente. Em todas as sociedades de que temos conhecimento, desde a mais primitiva até o estágio atual do capitalismo contemporâneo, a transformação da natureza nos meios de produção e meios de subsistência para a reprodução social sempre existiu - esta é uma condição eterna -, o que se modifica no curso da história é a forma pela qual as atividades de produção/consumo e distribuição são organizadas e realizadas. Mudam os objetos produzidos, as formas de transformá-lo e sua distribuição, porém, não se elimina o fato da necessidade do metabolismo entre o homem e a natureza, 
condição eterna do ser social (Marx e Engels, 2007; Moradillo, 2010).

É a partir do trabalho como intercambio do homem com a natureza que novas necessidade e possibilidades vão sendo postas, remetendo para além do trabalho, criando novas mediações sociais a exemplo da filosofia, arte, ciência, religião, direito, Estado, família, dentre outras. O trabalho é o modelo das objetivações humanas, pois todas elas supõem as características constitutivas do trabalho: teleologia, universalização e linguagem (Neto \& Braz, 2009).

Esse processo de construir a si mesmo, de construir ambientes cada vez mais sociais para dar conta da sua reprodução caracteriza a essência do homem. Quando, por determinados processos de objetivação, essa essência do homem é negada, dá-se a alienação (Mészáros, 2006b; Marx, 2006; Neto, 2009). A alienação corresponde à negação do humano, a criação de formas objetivas que impedem a plena explicitação do gênero humano, a negação da práxis social.

A alienação propiciada pelo capital impõe aos seres humanos, no seu dia a dia, na sua cotidianidade, não reconhecê-lo como uma criação sua. Ele, o capital, passa a ser uma força natural como qualquer outra existente na natureza. Opera-se uma inversão na nossa subjetividade: o ser humano é subsumido pelo capital, o processo de objetivação humana é negativado; o ter passa a assumir o ser (Marx, 2006).

Ao analisar a sociedade da sua época, Marx (1980; 2006), considerava que capital e pleno desenvolvimento humano o homem inteiro, explicitação da sua genericidade - são excludentes, não se articulam, se negam, são antagônicos; com toda consequência nos planos: ético, político, econômico e educacional. A formação humana omnilateral passa a ser uma impossibilidade objetiva.

Marx (2006), nos Manuscritos de Paris, de 1844, ao discutir a propriedade privada e o comunismo, desenvolve a questão do estranhamento de todos os sentidos humanos, físicos e intelectuais, por um novo sentido que aparece na sociedade burguesa, baseado na propriedade privada, isto é, o sentido do ter. Esse vai se tornar o verdadeiro sentido social.

É, portanto, a partir desse estranhamento que o trabalho passa gradativamente de criador a destruidor, deixando de ser uma atividade de forças livres para se tornar trabalho forçado, simples meio de sobrevivência, deixando de ser explicitação de todas as potências físicas e intelectuais humanas para se tornar seu definhamento. Então, ele nega 
seu próprio princípio e nega assim o princípio mesmo do homem.

Esta forma de ser do trabalho é nefasta para o ser social que busca a omnilateralidade e que, sob a forma do trabalho alienado, vivencia a unilateralidade. $\mathrm{O}$ homem se torna um fragmento de si próprio, sendo sobrepujado por sua própria obra, deixando de ser ele mesmo. Humaniza a natureza, mas não desenvolve a humanidade de sua natureza, passa a ser expressão da coisificação do seu ser, da reificação do capital (Marx 2006; Marx e Engels, 2007).

\section{Economia política: teoria do valor- trabalho}

Defendemos que num curso de formação de professores não basta explicitar a categoria trabalho no seu sentido ontológico e os seus desdobramentos para a reprodução do ser social, sentimos também a necessidade de trazer o outro pilar necessário para desmistificar a realidade social: os princípios da economia política a partir da teoria do valor-trabalho.

Assim, juntamente com Marx (1980, 2006), que floresceu de 1818-1883 e foi contemporâneo das transformações realizadas pela burguesia revolucionária, vivendo os efeitos políticos da revolução francesa, da revolução industrial com seu ápice na Inglaterra e no plano das ideias filosóficas tendo como referência principal a Alemanha, considerada a mais desenvolvida nesse campo, perguntamos: o que é o capital? Como é possível a riqueza?

Essas são algumas das inquietações de Marx, que passa a ter como objeto de estudo a sociedade burguesa do seu tempo, que do ponto de vista ideopolítico e técnico-cientifico se consolidará no final do século XVIII e durante boa parte do século XIX - a fase do capitalismo industrial $^{\mathrm{vi}}$-, após o longo processo de acumulação primitiva, que inicia na transição do feudalismo para o capitalismo nos séculos XV/XVI.

Com as contribuições de Engels, inicialmente na década de 1840, principalmente com relação às questões da economia política, Marx envereda por um longo processo para explicar a tríade fetichóide: mercadoria, dinheiro e capital e como é possível a riqueza na sociedade burguesa (Moradillo, 2010).

Nos manuscritos de Paris, de 1844, Marx expõe, a partir de uma perspectiva moralista, o problema do dinheiro: da "divindade visível”, da "prostituta universal", "o proxeneta universal dos homens e dos povos", como Shakespeare denomina (Marx, 2006, p. 159). 
No livro 1 do Capital, de 1867, após exaustivos estudos para compreender a sociedade burguesa da sua época, Marx (1980) explica o dinheiro de forma científica, de como a tríade fetichóide funciona.

Marx (1980) tem como ponto de partida, na sua pesquisa, nos seus estudos, a noção de riqueza e não de mercadoria. Não qualquer forma histórica de riqueza, mas aquela que domina o modo de produção capitalista, que aparece como uma "imensa acumulação [coleção] de mercadorias" (Marx, 1980, p. 41). Ele parte da forma fenomênica, daquilo que aparece na sociedade capitalista. Nesse momento, após perquirir por longo tempo o seu objeto de estudo, a sociedade civil burguesa, e tecer a crítica da economia política, historicizando-a, encontra-se ele em condições de analisar a mercadoria, e afirma: "a mercadoria, isoladamente considerada, é a forma elementar dessa riqueza" (Marx, 1980, p. 41).

Pela manifestação da riqueza na sociedade capitalista, procura ele as suas contradições e incongruências, por isso a necessidade de ir às mercadorias, para elucidar as suas artimanhas, seus nexos e significados dentro de relações sociais. A mercadoria é um objeto prático, que tem uma utilidade e satisfaz alguma necessidade humana, contém vida social e carrega com ela essa tensão de ser valor de uso (mais propriamente uso) e de troca (mais propriamente valor). A mercadoria é a "célula" da sociabilidade mercantil, o elemento que particulariza a totalidade capitalista, a parte que contém a totalidade.

A partir desse ponto, Marx destrincha a fenomenologia da sociedade capitalista, expondo os dois fatores da mercadoria: o valor de uso e o valor de troca e sua contradição. Mostrará que a substância do valor de uso é o trabalho concreto, que serve de pedestal para o trabalho abstrato, ou melhor, o valor. Como na sociedade capitalista o que importa não é o valor de uso para satisfazer necessidades humanas e sim a troca, onde o valor se valoriza, a contradição se instala.

Ao desmontar a mercadoria, Marx mostra que o valor de uso é histórico, contingente, tem como base as qualidades imanentes ao trabalho concreto na sua capacidade de converter a natureza em objetos práticos, úteis, podendo se converter em mercadoria ou não. Essa é a "condição eterna" do homem, da existência do ser social, metabolismo necessário a qualquer agrupamento humano historicamente existente. É impensável uma sociedade que não produza os meios de subsistência dela mesmo.

Marx mostrará que o valor das coisas tem a ver com o trabalho humano 
incorporado nelas e sua magnitude com o tempo de trabalho (médio) socialmente necessário para produzi-las. Essa é a essência da teoria do valor-trabalho. É isso que interessa para Marx, o valor é nada menos do que atividade humana incorporada nas coisas, é relação social historicamente determinada, configurada. O valor é expressão do desenvolvimento social da humanidade ${ }^{\text {vii }}$.

O trabalho de intercâmbio orgânico com a natureza, de condição eterna do homem - esse é seu sentido positivo -, assume na sociedade capitalista a sua máxima alienação, o seu sentido negativo, pois se torna mercadoria: deixa de ser produtor de valores de uso para ser produtor de valor, de mais valia ${ }^{\text {viii }}$. Esse é o seu conteúdo histórico.

Assim, podemos afirmar, a partir de Marx, que dentro da realidade social atual, determinada por relações capitalistas de produção, a riqueza é fruto da apropriação por parte de alguns - os donos dos meios de produção - do trabalho produtivo de muitos, que no dia a dia, por estarem apartados dos meios fundamentais de produção da nossa existência, tem que vender a sua força de trabalho para dar conta da sua existência - se torna uma mercadoria -, se alienando nesse processo.

Podemos afirmar, ainda com Marx (1980), que por esse caminho tortuoso que tem exaurido o trabalhador e destruído a natureza, a sociedade capitalista propiciou à humanidade o desenvolvimento das forças produtivas a tal ponto que é possível superar as carências individuais e sociais o reino das necessidades -, tornando plena a possibilidade do reino da abundância e, com isso, possibilitando um salto da humanidade para outro patamar de sociabilidade, uma verdadeira comunidade, o comunismo. Porém, dentro de relações sociais de classe, isso não pode se configurar. A lógica do capital não visa à reprodução do ser social como fundamento e sim à valorização de valor através da "esfola" do trabalhador, que vende sua força de trabalho (Moradillo, 2010).

Finalizamos esse item com a seguinte síntese: o ser social é uma totalidade, um complexo de complexos (Lukács, 2010); para compreender qualquer parte dessa totalidade (complexo), devemos sempre buscar a gênese e a função social de cada complexo constitutivo dessa totalidade complexa. Por gênese entendemos não só a origem histórica, mas, sobretudo, sua origem ontológica. Para nós, a partir de Lukács (2010), a função social de determinado complexo significa a função que essa determinada parte desempenha na reprodução do ser social. É buscando a gênese e a função social que se descobre 
sempre a natureza mais íntima de determinada parte da realidade social (Tonet, 2007).

Ainda que o trabalho seja o fundante do ser social, constitui apenas um dos momentos da realidade social. Desde o seu momento original, outros momentos comparecem, como a sociabilidade, a linguagem e a consciência. A educação aparece desde os primórdios na necessidade de compartilhar experiências de sentido gregário. Outros vão surgir com o desenvolvimento das forças produtivas e aumento da complexidade da sociedade. $\mathrm{O}$ trabalho é a única categoria cuja função social é a produção dos bens materiais necessários à existência humana. Essa é uma constatação ontológica, é a condição eterna do ser social (Marx, 1980; 2006). A partir do trabalho surgem as outras atividades humanas. Entre o trabalho e as outras atividades humanas existe uma dependência ontológica, todas têm uma autonomia relativa, já que não dependem mecanicamente do trabalho; havendo uma determinação recíproca entre todas elas, que se relacionam e se constituem mutuamente nesse processo (Tonet, 2007).

Após essa leitura, o leitor pode se questionar: é necessário que um professor de Ciências da Natureza do campo conheça todos os princípios tratados até aqui? Quais as relações destas concepções com a prática pedagógica do professor? Entendemos que essas questões podem aparecer diante do atual pragmatismo que assola a formação docente, seja no campo ou na cidade, que busca respostas imediatas que desemboquem na sua prática pedagógica. $\mathrm{O}$ grande problema desse imediatismo e recuo teórico na formação docente é que sem as discussões que fizemos anteriormente, a tão propalada "educação crítica" fica esvaziada de sentido, vira um refrão vazio que ressoa sem dizer quase nada. Desfetichizar o que é o ser humano do ponto de vista ontológico como a sociedade regida pelo capital acumula riqueza e exaure o trabalhador é imprescindível para que o professor de Ciências da Natureza encontre ressonância destas concepções nos seus pressupostos pedagógicos e educacionais, evitando, assim, cair nas armadilhas dos discursos modernos educacionais, que na aparência se dizem críticos e progressistas, mas que nas suas bases servem como instrumento ideológico da burguesia.

E quais são, então, esses princípios educacionais e pedagógicos gerais? É com o que nos deteremos no próximo item deste trabalho.

\section{c) Pressupostos e princípios educacionais e pedagógicos gerais}


A educação como um complexo social, que tem como função garantir que as novas gerações se apropriem do legado de conhecimentos, habilidades e valores sociais conquistados pelas gerações precedentes e a atual - garantir a reprodução social -, está compelida a cada instante a lidar com a tensão dialética entre o momento da conservação e da transformação, sendo que o polo da transformação põe em evidencia a relação entre outras duas categorias fundamentais para uma educação crítica: necessidades e possibilidades. As necessidades e possibilidades produzidas em cada momento da história social da humanidade, tanto ao nível do indivíduo como no da totalidade social, põem novas determinações e movimento na esfera da reprodução social, fazendo com que o polo da transformação esteja sempre presente no ato educativo (Moradillo, 2010).

Por isso, defendemos que o professor, em sua práxis, deve ter claro para que tipo de prática social está formando os indivíduos, qual é o projeto histórico de sociedade almejado.

O professor tem que ter clareza de que a constatação que se faz da realidade precisa ser interpretada, julgada. É preciso ter um juízo de valor. Aqui aparece a questão de classe. Não tem como, numa sociedade que se estrutura na distinção de classes sociais, entre aqueles que produzem a riqueza e aqueles que se apropriam dela, o professor deixar de se posicionar eticamente. Ao valorar, ele também projeta, toma posição de classe e propõe a sociedade e o homem que se quer formar e que se almeja. Por isso, o projeto político-pedagógico expressa essa intencionalidade, é uma ação interessada, deliberada, que compõe estratégias transformativas ou conservadoras. Os conteúdos a serem ensinados, a relação com os alunos, os referenciais científicoculturais e a metodologia que se adota expõem, além do máximo desenvolvimento cultural da humanidade, o compromisso de classe (Soares, 1992).

Pelo que já foi exposto até aqui, percebemos que defender a perspectiva sócio-histórica na formação de professores é conceber o trabalho no seu sentido ontológico: como fundante do ser social e que sempre remete para além dele mesmo, criando, assim, o mundo da cultura, das objetivações humanas, expressas nos objetos matérias, ideias e instituições. Dessa forma, o trabalho é também categoria central para entendermos a produção do conhecimento. Essa é a sua dimensão epistemológica.

No Projeto Político-Pedagógico PPP da área das Ciências da Natureza do curso Licenciatura em Educação do 
Campo, defendemos o trato com o conhecimento e a organização do mesmo a partir das categorias da totalidade social, da mediação e da contradição dialéticas, tendo sempre o trabalho como fundante do ser social, no seu movimento histórico, no contexto sócio-histórico. Assim, é possível articular a educação e a ciência com as questões políticas, econômicas, éticas, socioambientais e epistemológicas, dentre outras, em cada momento histórico, através de um método que incorpore o categorial/lógico e o histórico como dimensões do real (Moradillo et al., 2011).

Por isso, o PPP do curso deve ter como princípio a educação pelo trabalho como um processo de formação humana. Educação pelo trabalho considera o trabalho como princípio educativo, compreendendo o trabalho como fundante do ser social e que se expressa no tempo como intercâmbio orgânico entre o homem e a natureza. Sendo assim, os conteúdos escolares devem expressar o modo pelo qual o homem dominou e domina a natureza para produzir sua humanidade, diferentemente da educação para o trabalho, em que se pressupõe uma formação profissional para atuação no mercado de trabalho (Kuenzer, 2005; Pistrak, 2006). Disto não decorre afirmar que não seja importante a formação para a vida produtiva, para o trabalho. O que defendemos é uma formação "pelo" trabalho - emerge aí a história social do homem, que, no momento adequado, desemboca na formação "para" o trabalho, para uma profissão, com o fim de proporcionar aos sujeitos sociais vida produtiva, de acordo com as necessidades da reprodução da totalidade social. É lógico que numa sociedade que visa formar mão de obra para suprir as necessidades do capital, a educação "para" o trabalho se apresenta desde os primeiros anos escolares para os filhos da classe trabalhadora, e o interesse da totalidade social aparece com seu viés classista, ou melhor, como interesse da classe dominante. Este é um dos limites existentes na sociedade capitalista para termos uma educação que esteja pautada "pelo" trabalho e não "para" o trabalho. É possível tencionar por dialeticidade nessa contradição, e avançarmos nos cursos em que podemos trazer essa abordagem (Moradillo, 2010).

Desse modo, a educação pelo trabalho passa a ser princípio educativo e ponto focal de qualquer processo educativo que tem como pressuposto a emancipação humana.

É pertinente reafirmar e deixar claro que o trabalho como princípio educativo expressa essa dupla dimensão: ontológica (fundante do ser social, nossa protoforma) 
e epistemológica (os conhecimentos são produzidos por dentro de relações sociais, para dar conta da nossa existência, tendo o trabalho, na sua forma histórica concreta a sua base).

$\mathrm{Na}$ nossa prática educativa, a explicitação e execução de ações que levam em consideração a educação pelo trabalho conseguem colocar em evidência as contradições relativas aos conflitos sociais, políticos, éticos, ambientais e filosóficos que permeiam a sociedade atual, a partir do referencial teóricometodológico do materialismo histórico e dialético (Moradillo, 2010; Moradillo et al., 2011).

Os pressupostos da formação docente, acima mencionados, implicam em um currículo no qual se discuta o trabalho como fundante do ser social, correntes epistemológicas e sua consequência na produção do conhecimento científico, o papel da história no ensino de ciências, relações entre ciência, tecnologia e sociedade no seu movimento histórico, discussões sobre ética e ambiente na sociedade contemporânea, a geopolítica mundial dominante, com sua dualidade estrutural: campo x cidade, as relações entre as formas de produzir conhecimento, bens materiais e valores sociais. Um currículo dessa natureza tem como objetivo romper com as perspectivas idealistas de educação e superar a matriz curricular de base empírico-analítica que tem predominado nos cursos de formação de professores de ciências (Moradillo, 2010; Moradillo et al., 2011).

Para esse propósito, leva-se em consideração a organização dos componentes curriculares por área de conhecimento $^{\text {ix }}$, trabalhando de forma a buscar a interdisciplinaridade ${ }^{\mathrm{x}}$ de conteúdos formativos socialmente relevantes, através do sistema de complexos proposto por Pistrak (2006), objetivando a auto-organização dos estudantes e a realidade como base da produção do conhecimento, a prática social como ponto de partida e de chegada (Pistrak, 2006; Saviani, 2006).

O sistema de complexos foi apresentado por Pistrak (2006), educador do período pós-revolução russa, como a "organização sintética de todo o ensino" (Pistrak, 2006, p. 132), do programa, não como "uma técnica metodológica de organização do programa" (Pistrak, 2006, p. 133) tendo como finalidade "ajudar o aluno a compreender a realidade atual de um ponto de vista marxista, isto é, estudála do ponto de vista dinâmico e não estático" (Pistrak, 2006, p. 134). Desse modo, propunha a organização do trabalho pedagógico através de um sistema que garante a compreensão da realidade atual 
de acordo com o método dialético, através de aproximações sucessivas, como "elos numa única corrente” (Pistrak, 2006, p. 137), e procurando desenvolver a autoorganização dos estudantes.

A partir da nossa experiência, defendemos que os complexos: Sociedade, Natureza, Trabalho e Educação sejam estudados por todas as áreas de um curso de Licenciatura em Educação do Campo e, no caso da área das Ciências da Natureza, o complexo Recursos Sócio-Naturais seja abordado, trazendo as especificidades da área (química, física e biologia). Esses complexos foram escolhidos devido ao seu caráter geral (é necessário buscar os "elos da corrente" para dar conta de cada um deles) e o seu vínculo com o plano social: não são fortuitos, nem insignificantes e se ligam à histórica luta dos explorados contra os exploradores. O Sistema de Complexos contribui para a apropriação de questões filosóficas, artísticas, da cultura corporal e da ciência moderna com a compreensão de sua aplicação técnica, permitindo aos estudantes, além da percepção crítica, uma intervenção ativa na sociedade, com seus problemas, interesses, objetivos e ideais (Colavolpe \& Taffarel, 2009).

$\mathrm{Na}$ ação pedagógica, considerando o sistema de complexos de Pistrak como organizador do currículo e do ensino, a pedagogia que melhor se alinha aos nossos princípios e pressupostos filosóficos, dentro da nossa experiência, é a Pedagogia Histórico-Crítica - PHC (Saviani, 2006). Para Saviani (2006), proponente das bases da PHC, "O trabalho educativo é o ato de produzir, direta e intencionalmente, em cada indivíduo singular, a humanidade que é produzida historicamente e coletivamente pelo conjunto dos homens", sendo necessária, para isso, a “identificação dos elementos culturais que precisam ser assimilados pelos indivíduos da espécie humana para que eles se tornem humanos" através de "formas mais adequadas para atingir esses objetivos" (Saviani, 1995, p. 17).

A PHC entende a educação como "atividade mediadora no seio da prática social global" (Saviani, 2006, p. 74) em que professores e estudantes são "agentes sociais" "não antagônicos" (Saviani, 2006, p. 70 e 82). Sendo assim, a educação é, ela mesma, uma prática social condicionada pelo todo social e de natureza histórica. A Pedagogia Histórico-Crítica toma tais pressupostos como ponto de partida para a ação educativa que, tendo como objetivo contribuir para a libertação dos dominados e a inclusão dos excluídos, priorizando os conteúdos, pois “sem conteúdos relevantes, conteúdos significativos, a aprendizagem deixa de existir, ela transforma-se num 
arremedo, ela transforma-se numa farsa" (Saviani, 2006, p. 55). Os conteúdos da cultura são fundamentais por se constituírem em instrumentos indispensáveis para a participação política das camadas populares que, desse modo, poderão fazer valer os seus interesses frente aos dominadores, e assim participar efetivamente das discussões das questões sociais visando a sua transformação.

Saviani (2006 propõe uma sequência de ações como momentos da atividade educativa: partir da realidade (imediata, caótica), problematizar a realidade, instrumentalizar o educando (análise), realizar a catarse (síntese), estabelecimento de nova visão da realidade (mediada, rica de determinações).

Sendo assim, na área das Ciências da Natureza, o ensino de ciências deve problematizar a prática social em que o educando está inserido - o imediato, o singular/particular - ou seja, o cotidiano, que se apresenta de forma sincrética, e é aparentemente caótico. A partir desse ponto cabe ao processo educativo trazer as mediações necessárias - conhecimentos como instrumentos de pensamento - para a apropriação da realidade social na sua totalidade, na sua concretude, o concretopensado.

A problematização que defendemos a partir da PHC permite colocar em evidência os problemas a serem solucionados e suas contradições que só podem ser resolvidas a partir de uma ação teórica consubstanciada em uma concepção de realidade que a entenda como histórica, contingente e transitória e que só pode (deve!) ser abordada do ponto de vista material ou da luta dos seres humanos pela existência, isto é, tendo o trabalho como fundante do ser social (Marx, 2006; Marx \& Engels, 2007).

$$
\text { Por isso, para a }
$$
instrumentação/análise, é necessário tratar o conhecimento científico escolar dentro da abordagem sócio-histórica, na qual o sujeito social e a ciência fazem parte de um mesmo movimento histórico em que parte e totalidade estão articuladas. Dessa maneira, no ensino de ciências, não basta tratar os produtos da mesma, é preciso tratar também dos processos, isto é, não basta somente o ensino de ciências, mas também o ensino sobre a ciência (Matthews, 1995).

A partir da análise sócio-histórica, em que parte e totalidade estão articuladas, onde o lógico/categorial e o histórico são constitutivos da realidade social, podemos chegar a uma síntese rica de determinações, propiciando o processo catártico e, retornando ao problema que deu origem ao processo educativo/de ensino, a tendência é que o estudante 
participante do mesmo esteja em um patamar superior de conhecimento, não só do ponto de vista quantitativo, mas, sobretudo, do ponto de vista da metodologia de análise (onde os pressupostos ontológico e epistemológico são explicitados), elevando a qualidade do seu pensamento e da sua ação social.

Em consonância com a organização do ensino proposta por Pistrak (2006) e do ensino através da PHC, defendemos que no processo formativo dos estudantes da área das Ciências da Natureza também seja explicitado como se dá o processo de aprendizagem, dentro da perspectiva crítico-dialética, tendo como referência a teoria do desenvolvimento humano da Escola de Vigotski, também denominada de Psicologia Histórico-Cultural.

Partimos do pressuposto de que a Escola de Vigotski traz uma perspectiva materialista do processo de gênese e desenvolvimento do ser social e do seu psiquismo. A tarefa à qual a Psicologia Histórico-Cultural se detém é estudar o psiquismo humano superando a dicotomia da ciência psicológica que explica a psique humana, ora por vias organicistas, ora por vias idealistas a-históricas (Luria, 1979; Vigotski, 2009; Martins, 2013). A superação de tal dicotomia implica fazermos uma análise dialética que entende o ser humano não como um somatório de fatores naturais e sociais ou como um ser que se adapta numa relação homem meio. $\mathrm{O}$ entendimento dialético requer assumir que, na apropriação cultural, o sujeito (trans)forma seu psiquismo, ou seja, dá uma nova forma ao seu modo de pensar e sentir o mundo que não pode ser mais explicada pela via biológica, mas a incorpora por superação (Martins, 2013; Messeder Neto, 2016).

Vigotski encontrará no signo a ferramenta psicológica central para que esse psiquismo possa sofrer a transformação cultural que supera, por incorporação, os limites biológicos. É o signo que se interpõe entre o sujeito e o mundo e medeia as transformações do psiquismo humano, permitindo que o sujeito deixe de ser refém dos estímulos imediatos e passe a ter controle da sua conduta (Vigotski, 2009).

A palavra é, para Vigotski, o signo dos signos. O desenvolvimento do significado das palavras representa para a Psicologia Histórico-Cultural as mais amplas possibilidades de desenvolvimento do pensamento do sujeito. Esses significados trazem uma síntese, em termos de pensamento, daquilo já produzido no seio da cultura, e que é compartilhada com o sujeito à medida que ele vai se apropriando destes significados. 
O desenvolvimento do psiquismo humano passa, portanto, pela aprendizagem dos conceitos já construídos pela humanidade, caracterizando o processo de formação dos sujeitos como um processo educativo. Não por acaso, Vigotski tratará a aprendizagem como promotora do desenvolvimento, sendo na relação do processo de apropriação da cultura humana que as faculdades psíquicas se transformam e se humanizam.

A Psicologia Histórico-Cultural conferirá grande importância à educação escolar, já que esta teria como função disponibilizar para os sujeitos os significados mais elaborados e que melhor generalizam as propriedades dos objetos e fenômeno. Esse sistema de significados de máxima generalização é chamado por Vigotski de conceitos científicos. A real aprendizagem desses conceitos projeta o psiquismo do sujeito a novos patamares, permitindo que ele compreenda o mundo e a si mesmo para além dos limites imediatos e pragmáticos da vida cotidiana, numa relação cada vez mais consciente com as produções do gênero humano.

O significado do conceito se desenvolve, muda no tempo histórico, espelha a totalidade em processo do devir social a partir do trabalho. A importância disso? É que, no processo educativo, o ato de reproduzir ativamente as objetivações humanas significa muitas vezes não só a atividade de utilizar o objeto, mas também a atividade que reproduz o próprio objeto. E a reprodução do objeto, seja ele físico ou ideal, requer, para se tornar científico, a compreensão da sua gênese e de seu desenvolvimento a partir do trabalho, ato fundante do ser social. Isso tem a máxima importância para um projeto políticopedagógico que pense a educação nos seus vários níveis: fundamental, médio e superior, e que se preocupa em disponibilizar para as novas gerações, principalmente da classe trabalhadora do campo ou da cidade, os conhecimentos científicos socialmente relevantes conquistados pela humanidade.

$\mathrm{O}$ processo de produção da humanidade em cada sujeito de maneira intencional não é um trabalho fácil. Eis que esta é a tarefa do professor que não pode ser reduzida a um simples organizador de espaços ou facilitador de aprendizagens. $\mathrm{O}$ professor é o sujeito que ensina! Por ser o mais experiente, por deter o conhecimento acumulado e sistematizado naquele momento, por ter a prévia-ideação do processo - as finalidades da ação educativa, aonde se quer chegar, os objetivos -, por dominar a lógica e a historicidade daqueles conhecimentos, esse professor pode ser capaz de propiciar ao aluno, por intermédio da ação do mesmo em direção ao objeto de 
estudo, os nexos e significados do real para que aquele objeto do conhecimento tenha sentido, constitua signo.

Isso não significa negar a especificidade do aluno e suas mediações com o cotidiano. Está claro para nós que o professor de Ciências da Natureza da Educação do Campo precisa conhecer as especificidades locais, inclusive, para ajudar os estudantes na construção dos significados científicos. Mas, não significa que isso deve se converter em uma química do campo, uma física do campo, uma biologia do campo etc. A grande potência dos conhecimentos científicos, está na generalização que se materializa nos diversos exemplares. Sendo assim, o professor pode até partir das vivências e relações do campo para ensinar conceitos, mas não pode parar aí, se quiser de fato fazer esses estudantes alçarem voos com pensamento conceitual. A riqueza do processo educativo, pelas vias do pensamento conceitual cientifico, está na possibilidade do conhecimento da realidade local ao mesmo tempo em que nos reconhecemos como seres humanos e entendemos o mundo para além dos cárceres da imediaticidade pragmática.

Nesse momento, finalizamos essa parte da fundamentação colocando os limites históricos que configuram os níveis individual e social das nossas intervenções. A educação por si só não tem o poder de transformar a sociedade. Podemos, sim, contribuir de forma revolucionária, disponibilizando à classe trabalhadora os conhecimentos socialmente conquistados pela humanidade e que lhes são negados pela sociedade de classes, elevando a sua consciência de classe e potencializando a sua ação educativa e social (Moradillo et al., 2011).

\section{Conclusão}

Diante do exposto, saímos na defesa de que o Projeto Político-Pedagógico da área das Ciências da Natureza dos cursos de Licenciatura em Educação do Campo deve ter como pano de fundo a forma com que o ser humano produz e reproduz a sua existência a partir do trabalho, produzindo o mundo da cultura, com seus vários complexos sociais que vão sendo produzidos historicamente, a exemplo da educação, para dar conta da sua existência/reprodução.

Torna-se fundamental nessa abordagem compreender a educação como um complexo social que se originou nos primórdios do desenvolvimento do ser social e que surge - para além do trabalho de intercâmbio com a natureza - com a função social de garantir para as novas 
gerações os conhecimentos, habilidades e valores sociais conquistados pelo agrupamento social/comunidade ao qual pertence, através da transmissão dos mesmos. Por isso, para nós, é sempre importante compreender e explicar a educação através da sua relação reflexiva com a sociedade (totalidade social), no seu movimento histórico, compondo uma unidade indissolúvel que foi perdida em muitos cursos de formação de professores.

Dessa relação reflexiva, dois pilares são fundamentais para compreender $\mathrm{e}$ explicar a sociedade: a ontologia do ser social: o que é o ser social? Como ele produz e reproduz a sua existência? E a economia política, tendo como referência a teoria do valor-trabalho. A partir desses dois pilares, teremos o trabalho como categoria fundante do ser social e modulador da práxis social. No PPP, a categoria trabalho assume também o papel articulador do conhecimento e passa a ser princípio educativo. Com base nesses fundamentos gerais, macro estruturantes, concebendo o trabalho como categoria axial, é possível, agora, articular os conhecimentos específicos da ciência, da educação e da pedagogia, sempre em seu movimento categorial/lógico e histórico com a totalidade social e entre si.

Defendemos, portanto, um PPP e um currículo para os cursos de Licenciatura em Educação do Campo, em especial para a área das Ciências da Natureza, que tenha como pressuposto a concepção sóciohistórica de homem, natureza e sua relação, a partir do trabalho, com suas consequências na concepção de sociedade, conhecimento, ciência, educação, ensino e aprendizagem, dentre outras; possibilitando, dentro dos limites postos na sociedade atual, a superação das perspectivas idealistas de educação e de ciência empírico-analítica.

Dessa forma, esses princípios e pressupostos filosóficos, educacionais e pedagógicos apresentados visam formar professores que irão atuar na educação do campo, em especial do $6^{\circ}$ ao $9^{\circ}$ ano do ensino fundamental e no ensino médio, levando em conta a realidade do campo do ponto de vista sócio-educacional -, e indo além - uma educação universalizante , através de ações pedagógicas que explicitem a educação como um direito das pessoas que vivem no campo e como ferramenta de desenvolvimento e transformação social.

Ao trazer a abordagem sóciohistórica e ao trabalhar a perspectiva historicizadora do homem e da realidade social no currículo da área das Ciências da Natureza dos cursos de Licenciatura em Educação do Campo, acreditamos que estamos avançando no sentido da luta 
contra hegemônica na educação e na sociedade, na buscada emancipação humana.

\section{Referências}

Coggiola, O., \& Katz, C. (1996). Neoliberalismo ou crise do capital? São Paulo, SP: Xamã.

Colavolpe, C. R., \& Taffarel, C. N. Z. (2009). Sistema de Complexo Temático: uma contribuição para o debate de reestruturação curricular do Curso de Educação Física da UFBA. Rascunho Digital. Salvador: UFBA.

Duarte, N. (2016). Os conteúdos escolares e a ressurreição dos mortos: contribuição à teoria histórico-crítica do currículo. Campinas, SP: Autores Associados.

Hall, S. (2001). A identidade cultural na pós-modernidade. Rio de Janeiro, RJ: DP\&A.

Kuenzer, A. et al. (2005). Ensino médio: construindo uma proposta para os que vivem do trabalho. São Paulo, SP: Cortez.

Leontiev, A. (2004). O Desenvolvimento do psiquismo. São Paulo, SP: Centauro.

Lyotard, J. (1997). A condição pósmoderna. Lisboa: Gradiva.

Lukács, G. (2010). Prolegômenos para uma ontologia do ser social: questões de princípios para uma ontologia hoje tornada possível. São Paulo, SP: Boitempo.

Luria, A. R. (1979). Curso de psicologia geral: introdução evolucionista à psicologia. Rio de Janeiro, RJ. Civilização Brasileira.
Malanchen, J. (2016). Cultura, conhecimento e currículo: contribuições da pedagogia histórico-crítica. São Paulo, SP: Autores Associados.

Maldaner, O. A. (2007). Situações de Estudo no Ensino Médio: nova compreensão de educação básica. In Nardi, R. (Org). A pesquisa em Ensino de Ciências no Brasil: alguns recortes (pp. 237-253). São Paulo, SP: Escrituras.

Marx, K. (1980). O Capital (crítica da economia política): o processo de produção do capital.___ Civilização Brasileira.

Marx, K. (2006). Manuscritos econômicofilosóficos. São Paulo, SP: Boitempo.

Marx, K., \& Engels, F. (2007). A ideologia Alemã. São Paulo, SP: Boitempo.

Martins, L. M. (2013). O desenvolvimento do psiquismo e a educação escolar: contribuições à luz da psicologia históricocultural e da pedagogia histórico-crítica. Campinas, SP: Autores Associados.

Massena, E. P. (Org.). (2015). Situação de estudo: processo de significação pela pesquisa em grupos interdisciplinares. Ijuí, RS: Ed. Unijuí.

Matthews, M. R. (1995). História, Filosofia e Ensino de Ciências: a tendência atual de reaproximação. Caderno Catarinense de Ensino de Física, 12(3), 164-214.

Messeder Neto, H. S. (2016). O lúdico no ensino de química na perspectiva histórico-cultural: além do espetáculo, além da aparência. Curitiba, PR: Editora Prismas.

Mészáros, I. (2006a). Para além do capital: rumo a uma teoria da transição. São Paulo, SP: Boitempo. 
Mészáros, I. (2006b). A teoria da alienação em Marx. São Paulo, SP: Boitempo.

Moradillo, E. F. (2010). A dimensão prática na licenciatura em química da UFBA: possibilidades para além da formação empírico-analítica (Tese de Doutorado). Universidade Federal da Bahia, Bahia.

Moradillo, E. F., Barbara, C. P., Messeder Neto, H., Sá, L. V., Cunha, M. B. M., Taffarel, C. Z., \& Perin, T. F. (2011). Licenciatura em Educação do Campo da Ufba: pressupostos e princípios filosóficos e pedagógicos. In Encontro de Pesquisa e Práticas em Educação do Campo, 2011, João Pessoa - Paraíba.

Moraes, M. C. M. (Org.). (2003). Iluminismo às avessas: produção de conhecimento e políticas de formação docente. Rio de Janeiro, RJ: DP\&A.

Pístrak, M. M. (2006). Fundamentos da escola do trabalho. São Paulo, SP: Expressão Popular.

Projeto Político Pedagógico (2008). Curso de Licenciatura em Educação do Campo. Faculdade de Educação da UFBA. Salvador-Bahia (não publicado).

Saviani, D. (1995). Pedagogia históricocrítica: primeiras aproximações. Campinas, SP: Autores Associados.

Saviani, D. (2006). Escola e democracia: teorias da educação, curvatura da vara, onze teses sobre a educação política. Campinas, SP: Autores Associados.

Silva, T. T. (1999). Documentos de identidade: uma introdução às teorias do currículo. Belo Horizonte, MG: Autêntica.
Soares, C. L. (1992). Metodologia do ensino de educação física. São Paulo, SP: Cortez.

Stedile, J. P. (Org). (2011). A questão agrária no Brasil: o debate tradicional 1500-1960. São Paulo, SP: Expressão Popular.

Tonet, I. (2007). Educação contra o capital. Maceió, AL: Edufal.

Vigotsky, L. S. (2009). A construção do pensamento e da linguagem. São Paulo, SP: Martins Fontes.

Wood, E. M., \& Foster, J. B. (Orgs.). (1999). Em defesa da história: marxismo e pós-modernismo. Rio de Janeiro, RJ: Jorge Zahar.

\footnotetext{
${ }^{\mathrm{i}}$ Este artigo é fruto de vários trabalhos publicados ao longo desses últimos 8 anos, tratando da formação de professores, em particular da área das Ciências da Natureza e Matemática da Licenciatura em Educação do Campo.

${ }^{\text {ii } U m ~ d o s ~ a u t o r e s ~ d o ~ m a n u s c r i t o ~ f o i ~ c o o r d e n a d o r, ~}$ juntamente com outro colega, da área das Ciências da Natureza e Matemática.

iii Reconhecemos a diversidade de posições teóricas e ideopolíticas que se encontram no espectro denominado de pós-moderno. Logo abaixo iremos fazer algumas considerações gerais sobre o pósmodernismo.
}

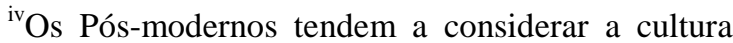
nos seus aspectos particulares, como aquilo que dá identidade a determinado grupo ou comunidade. Nesse artigo iremos tratar a cultura dentro da tradição marxista: como resultado acumulado das objetivações humanas a partir do trabalho ao longo da história (Malanchen, 2016).

Ver as reformas do Estado brasileiro proposta em 1995 por Bresser Pereira, Ministro da Administração e Reforma do Estado no governo de Fernando Henrique Cardoso (Sguissardi \& Silva Júnior, 2009).
} 


\begin{abstract}
${ }^{\mathrm{vi}}$ Ver Neto \& Braz (2009), dentre outros autores, sobre as três principais fases da sociedade capitalista: capitalismo mercantil (acumulação primitiva), capitalismo industrial e capitalismo monopolista/financeiro.
\end{abstract}

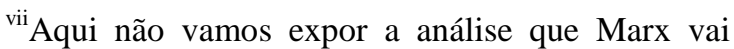
fazer a partir das trocas simples de produtos (valores de uso) até chegar a forma complexa, onde valor se valoriza. No entanto, defendemos que essa abordagem seja feita também nos cursos de formação de professores.

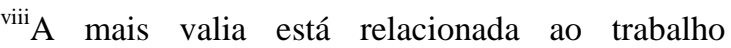
excedente produzido pela mercadoria força de trabalho.

${ }^{i x}$ Não abordaremos nesse texto as contradições que estão postas por trás da formação de professores por área de conhecimento, principalmente na conjuntura atual.

${ }^{x}$ A interdisciplinaridade tem como pressuposto a teoria do conhecimento que toma a realidade como totalidade e radicaliza na análise da realidade social, dentro do referencial teórico-metodológico baseado no materialismo histórico e dialético (Moradillo, 2010).

Recebido em: 09/07/2017

Aprovado em: 24/08/2017

Publicado em: 13/12/2017

\section{ORCID}

Edilson Fortuna de Moradillo

http://orcid.org/0000-0001-5457-3718

Hélio da Silva Messeder Neto

http://orcid.org/0000-0002-6620-2989

Elisa Prestes Massena

http://orcid.org/0000-0002-7670-0201
Como citar este artigo / How to cite this article / Como citar este artículo:

APA:

Moradillo, E. F., Neto, H. S. M., Massena, E. P. (2017). Ciências da Natureza na Educação do Campo: em defesa de uma abordagem sócio-histórica. Rev. Bras. Educ. Camp., 2(3), 991-1019. DOI: http://dx.doi.org/10.20873/uft.2525-

$\underline{4863.2017 \mathrm{v} 2 \mathrm{n} 3 \mathrm{p} 991}$

ABNT:

MORADILLO, E. F.; NETO, H. S. M.; MASSENA, E. P. Ciências da Natureza na Educação do Campo: em defesa de uma abordagem sócio-histórica. Rev. Bras. Educ. Camp., Tocantinópolis, v. 2, n. 3, p.

991-1019, 2017.2 DOI: http://dx.doi.org/10.20873/uft.25254863.2017v2n3p991 